DOI: http://dx.doi.org/10.22483/2177-5796.2018v20n1p133-147

\title{
Planejamento educacional e poder local na elaboração dos planos municipais de educação ${ }^{1}$
}

\author{
Elisangela Alves da Silva Scaff \\ Marli dos Santos de Oliveira \\ Flavia Paula Nogueira Aranda
}

Resumo: Este texto tem como objetivo apreender as particularidades atinentes ao planejamento educacional em nível local, particularmente no processo de elaboração dos Planos Municipais de Educação (PMEs) em dois municípios do Estado de Mato Grosso do Sul. A pesquisa foi desenvolvida a partir de documentos oriundos dos governos federal e municipal, reportagens difundidas nos veículos de comunicação e participação na elaboração dos planos desses municípios. As disputas em torno da tramitação e aprovação dos PMEs evidenciam a centralidade do poder político local, cuja condução do itinerário participativo nem sempre resulta em um plano que represente o ideário dos segmentos participantes, o que coloca o princípio da gestão democrática ainda como um desafio no plano local.

Palavras-chave: Planejamento educacional. Poder local. Planos municipais de educação.

\section{Educational planning and local power in the elaboration of municipal education plans}

Abstract: This study aims to know the particularities related to educational planning at the local level, especially in the process of elaborating Municipal Education Plans (PME's) in two municipalities of the Mato Grosso do Sul state. The research was carried out from documents originating from the federal and municipal governments, reports published in the media and participation in the elaboration of the plans of these municipalities. The disputes surrounding the SME process and approval demonstrate the centrality of local political power, whose conduct of the participatory itinerary does not always result in a plan that represents the ideas of the participating segments, which puts the principle of democratic management still as a challenge for the municipality.

Keywords: Educational planning. Local power. Municipal plans of education.

\footnotetext{
${ }^{1}$ Pesquisa desenvolvida com apoio financeiro do Conselho Nacional de Desenvolvimento Científico e Tecnológico (CNPq), Processo $n^{\circ}$. 408981/2013-0 e da Fundação de Apoio ao Desenvolvimento do Ensino, Ciência e Tecnologia do Estado de Mato Grosso do Sul (FUNDECT), Termo de Outorga 010/2016, e com Bolsa de Demanda Social da Coordenação de Aperfeiçoamento de Pessoal de Nível Superior (CAPES).
} 
SCAFF, Elisangela Alves da Silva; OLIVEIRA, Marli dos Santos de; ARANDA, Flavia Paula Nogueira. Planejamento educacional e poder local na elaboração dos planos municipais de educação.

\section{Introdução}

A década de 1980 é marcada pela abertura democrática em diversos países da América Latina, entre eles o Brasil. Esse momento histórico foi suscitado e, ao mesmo tempo, motivou o fortalecimento dos movimentos sociais e a ideia de participação popular, incidindo sobre a forma de atuação dos governos nacionais e locais.

Tal sistemática de construção das políticas públicas implica na reconfiguração do papel do Estado na sua relação com a sociedade, uma vez que cria elementos para a constituição do conceito de governança: “[...] um novo paradigma da ação pública estatal, em que o foco central das ações não se restringe aos órgãos e aparatos estatais, mas incorpora também, via interações múltiplas, a relação governo e sociedade" (GOHN, 2011, p. 41).

Weffort (1992) denomina esse movimento de "Novas Democracias" e atribui seu início à Revolução dos Cravos, realizada em Portugal, no ano de 1974, momento que inaugura uma "grande onda histórica, que passou pela Europa do Sul nos anos 70, e pela América Latina nos 80 [...]” (p. 5), cuja maior diferença em relação a outras formas democráticas está na participação da população adulta na consecução das políticas públicas (WEFFORT, 1992).

A ampliação do leque de sujeitos sociais no cenário democrático tem resultado na produção de diferentes engenharias participativas, com a criação de novas redes de participação, tornando o espaço local um "fértil laboratório de tecnologias de gestão social” (FLEURY, 2003, p. 17), posto que

É no plano local, especialmente num dado território, que se concentram as energias e forças sociais da comunidade, constituindo o poder local daquela região; no local onde ocorrem as experiências, ele é a fonte do verdadeiro capital social, aquele que nasce e se alimenta da solidariedade como valor humano (GOHN, 2004, p. 24).

Local aqui é compreendido para além do espaço físico do território, ou de uma instância administrativa do governo, na medida em que abarca também o espaço abstrato das relações sociais, indicando, portanto, “[...] movimento e interação de grupos sociais que se articulam e se opõem em relação a interesses comuns" (FISCHER, 1992, p. 106). Nessa perspectiva, poder local constitui-se em "[...] lugar de experiências multifacetadas com orientações nem sempre coerentes e coincidentes" (FERNANDES, 1992, p. 31) e, portanto, permeado pelo conflito.

Para Fernandes (1992), o fortalecimento do poder local representa a construção de novas fronteiras políticas no interior do Estado e a afirmação da democracia participativa, de forma a 
possibilitar a articulação entre o poder local e o poder nacional, cujo intento só pode se realizar por meio da elaboração de planos.

No Brasil, a Constituição Federal de 1988, ao outorgar aos municípios brasileiros o status de entes federativos, atribui a eles a responsabilidade pelo planejamento das políticas públicas, de forma a atender às demandas da esfera local, em interlocução com um projeto nacional. A autonomia política e administrativa atribuída aos municípios tem implicado numa maior complexidade na relação entre os entes subnacionais, visto as novas arenas de negociação e produção das políticas públicas (FERREIRA, 2013).

Na esfera do planejamento educacional, o Plano Nacional de Educação (PNE) 2014-2024, aprovado pela Lei no 13.005 de 2014 (BRASIL, 2014b), estipulou o prazo de um ano para que os entes subnacionais publicassem seus devidos planos, exigência que culminou em intensos movimentos nos estados e municípios em direção à organização da comunidade para o cumprimento de tal dispositivo legal. A formulação dos planos de educação, na medida em que devem contemplar os anseios da sociedade civil, implica em negociações, disputas e conflitos em torno do seu teor e da sua lógica de construção.

Considerando a relação entre planejamento educacional e poder local, o presente texto objetiva apresentar e discutir o processo de elaboração do Plano Municipal de Educação (PME) em dois municípios do estado de Mato Grosso do Sul (MS), quais sejam: Dourados e Naviraí. Localizados na mesorregião sudoeste do Estado, os municípios em tela encontram-se entre os sete mais populosos do $\mathrm{MS}^{2}$, sendo Dourados a segunda maior cidade do estado, com população estimada em 215.486 habitantes para 2016, e Naviraí com população estimada de 52.367 para o mesmo período (IBGE, 2016).

Tem-se como objetivo do texto apreender as particularidades atinentes ao planejamento educacional em nível local, particularmente no que se refere à coordenação do processo de elaboração dos PMEs e à participação dos diversos segmentos sociais, conforme requerido no caderno de orientações elaborado pelo Ministério da Educação (MEC) (BRASIL, 2014a). Buscase identificar, assim, as correlações de forças que se configuraram nesse processo, e o que indicam em relação às possibilidades e aos limites da participação social na formulação de planejamento educacional no âmbito local.

\footnotetext{
${ }^{2}$ O estado de Mato Grosso do Sul possui 79 municípios até o ano de 2016, de acordo com o IBGE. 
SCAFF, Elisangela Alves da Silva; OLIVEIRA, Marli dos Santos de; ARANDA, Flavia Paula Nogueira. Planejamento educacional e poder local na elaboração dos planos municipais de educação.

A pesquisa foi desenvolvida a partir de documentos oriundos dos governos federal e municipais, como leis, projetos, portarias e atas, bem como reportagens difundidas nos veículos locais de comunicação e participação direta nos processos de elaboração dos planos desses municípios, cujas informações foram analisadas à luz de referencial teórico atinente à temática em tela.

\section{Planos Municipais de Educação de Dourados e Naviraí: sujeitos e contexto de formulação}

A aprovação da Lei $n^{o}$ 13.005/2014 (BRASIL, 2014b) que dispõe sobre o PNE foi aguardada no âmbito dos estados e municípios da federação para que, a partir dela, pudessem se desdobrar os respectivos planos estaduais e municipais de educação construídos com a participação da comunidade. É nesse contexto que se situa a formulação dos Planos Municipais de Educação de Dourados e Naviraí.

A dinâmica desse processo teve início com a nomeação das comissões responsáveis pela elaboração dos respectivos Planos Municipais de Educação (PME`s), cujas recomendações do MEC colocam como imperativo:

Para iniciar o trabalho, é necessário verificar se existe, no município, legislação ou norma que atribua a competência de coordenação ou elaboração do Plano Municipal de Educação a uma determinada instância além da Secretaria de Educação, como o Conselho ou Fórum Municipal de Educação (BRASIL, 2014a, p. 9).

Em Dourados, a Resolução SEMED n 21, de 22 de abril de 2014, constituiu a comissão para elaboração e criação do PME do município. Tal comissão foi composta por 48 (quarenta e oito) membros, sendo 8 (oito) membros vinculados diretamente à Secretaria Municipal de Educação (SEMED), 6 (seis) membros de outras secretarias do município, como cultura, saúde e assistência social, 4 (quatro) membros da Câmara Municipal, além de representantes da Associação Comercial e Empresarial do município, Sindicado Rural de Dourados, Associação Pestalozzi de Dourados; Serviço Social da Indústria - SESI; Associação de Pais e Amigos dos Excepcionais -APAE; Faculdades e Universidades publicas e privadas, Conselho Tutelar, conselhos do Fundeb e Conselho Municipal de Educação, Sindicato Municipal dos Trabalhadores em Educação (SIMTED); Associações de Pais e Mestres - APM's, entre outros. A presidência da comissão foi designada a uma das assessoras da SEMED (DOURADOS, 2014). 
A “Comissão Coordenadora de Elaboração e Adequação do Plano Municipal de Educação de Naviraí/MS” foi instituída pela Portaria n ${ }^{\circ}$ 01, de 11 de março de 2015, sendo constituída pelo Gerente Municipal de Educação ${ }^{3}, 1$ (uma) representante da Gerencia, 2 (duas) representantes do Conselho Municipal de Educação, um representante do Conselho do FUNDEB e 1 (uma) representante de Instituição de Ensino Superior Privada. Tal documento designa ainda a "Equipe técnica de apoio", também presidida pelo Gerente Municipal de Educação, e sendo composta por 9 (nove) membros da Gerencia Municipal de Educação (GME) e os 4 (quatro) demais integrantes da comissão coordenadora (representantes do CME, do Conselho do FUNDEB e da IES privada).

Além destes, também são designados para a equipe técnica: 2 (duas) Gestoras da Educação Básica - Educação Infantil e Ensino Fundamental da Rede Municipal de Ensino, 1 (uma) Gestora da Educação Básica Ensino Médio, da Rede Estadual de Ensino; 1 (um) representante do Instituto Federal de Educação de MS e 1 (um) representante do Sindicato Municipal dos Trabalhadores em Educação - SIMTED. A coordenação da comissão foi designada à presidente do $\mathrm{CME}$, e a coordenação geral do PME ficou sob a responsabilidade do Gerente Municipal de Educação.

Observa-se que entre os 25 membros designados pela SEMED de Naviraí, 6 constam respectivamente na comissão coordenadora e na comissão técnica, de forma que o número de participantes nessas duas comissões fica reduzido a 19 pessoas, cujo trabalho acha-se diretamente vinculado à Gerência Municipal de Educação (GME), posto que, mesmo designando a presidente do CME como coordenadora do processo de elaboração do documento, a coordenação geral fica vinculada ao GME.

Análise das comissões constituídas nos municípios estudados permite constatar a centralidade político-administrativa do governo municipal no planejamento educacional local, que se expressa pela atuação da Secretaria Municipal de Educação de Dourados e da Gerencia Municipal de Educação de Naviraí na coordenação da elaboração dos seus respectivos PMEs. Registre-se que ambos os municípios não possuem Fórum Municipal de Educação.

Ainda que em Naviraí a presidente do CME figure como coordenadora desse processo, abaixo da coordenação geral exercida pela gerencia, em Dourados registra-se apenas um integrante do CME como participante da comissão. A participação do Sindicato Municipal de

\footnotetext{
${ }^{3}$ No município de Naviraí os órgãos de administração direta da Prefeitura são denominados “Gerência”, inexistindo a figura de Secretarias Municipais.
} 
Trabalhadores em Educação (SIMTED) fica mais evidente no município de Dourados, que contou com três integrantes na comissão de elaboração do PME, enquanto que em Naviraí apenas um representante desse sindicato figura na equipe técnica de apoio.

A nomeação tardia da comissão de elaboração do PME de Naviraí foi justificada pelo Gerente Municipal de Educação em função do atraso no recebimento das orientações da equipe da "Rede de Assistência Técnica para Adequação ou Elaboração dos Planos de Educação de MS UNDIME/SED/SASE/MEC" (OLIVEIRA, 2017, p. 86), cujos informativos começaram a chegar aos municípios em fevereiro de 2015.

Essa Rede de Assistência Técnica foi criada em 2013, sob a responsabilidade da Secretaria de Articulação com os Sistemas de Ensino do Ministério da Educação (SASE/MEC), como estratégia de assistência técnica aos entes federativos (ALMEIDA JÚNIOR, 2014). Para a efetivação desta rede, o MEC constituiu um comitê tripartite em parceria com o Conselho Nacional dos Secretários de Educação (CONSED) e com a União Nacional dos Dirigentes Municipais de Educação (UNDIME), que organizou a referida rede em todos os estados e no Distrito Federal, sendo composta por avaliadores educacionais com funções de Coordenador estadual, Supervisor geral, Supervisor e Técnico (PEREIRA; GROSSI JÚNIOR, 2016).

Duas outras instâncias figuram como orientadoras do processo de elaboração do PME nos municípios pesquisados, quais sejam, a União Nacional dos Dirigentes Municipais de Educação (UNDIME) e o Fórum Estadual de Educação (FEE-MS). A UNDIME é uma associação civil sem fins lucrativos, fundada em 1986 e com sede em Brasília -DF, que promove reuniões, seminários e fóruns com o objetivo de repassar informações e formação a todas as secretarias municipais de educação, dirigentes e equipes técnicas.

O Fórum Estadual de Educação (FEE-MS) foi criado pelo Conselho Estadual de Educação em 1997 e se caracteriza como um órgão permanente de consulta, de assessoramento e de deliberação de propostas para implantação, implementação e avaliação de políticas educacionais, com vistas a possibilitar a interlocução entre sociedade civil e governo. Os fóruns de educação assumem um importante papel na medida em que articulam os diferentes anseios com vistas ao planejamento participativo na formulação dos planos decenais de educação e em seu monitoramento.

Ente as orientações emanadas desses órgãos, foi possível localizar junto às comissões locais 6 (seis) informativos da "Rede de Assistência Técnica para Adequação ou Elaboração dos 
Planos de Educação de MS-UNDIME/SED/SASE/MEC”, encaminhadas aos municípios no período de 11 de fevereiro a 8 de abril de 2015. Entre eles destaca-se o Informativo n ${ }^{\circ} 003$, de 04 de março de 2015, que comunicou a realização de uma capacitação para os coordenadores das comissões municipais do PME, que ocorreria concomitante ao Seminário da União de Dirigentes Municipais de Educação de MS, nos dias 24 a 26 de março daquele ano em Campo Grande-MS, "tendo em vista a necessidade de orientar todos os municípios no processo de elaboração/adequação dos PME-MS" (REDE, 2015a).

No dia 08 de abril de 2015 o Informativo $n^{\circ}$ 006/2015 solicitou o envio do cronograma da comissão municipal com a descrição das etapas de trabalho visando à finalização do documento até 24 de junho de 2015. A data máxima estipulada para envio do cronograma foi o dia 13 de abril de 2015, impreterivelmente, o que corresponde ao prazo de cinco dias depois da solicitação. Enfatiza-se, nesse Informativo e no de nº 003/2015 a importância do cumprimento dos prazos estabelecidos (REDE, 2015b).

Embora os estados e municípios possuam autonomia para elaborar seus planos, independentemente das orientações do governo federal, no caso de Naviraí, MS, observa-se a espera pelas orientações da Rede de assistência técnica, o que possibilita constatar a dependência do ente federativo municipal em relação à União, bem como a importância do papel indutor da União junto aos municípios. Já em Dourados, cuja comissão foi constituída em abril de 2014, a primeira reunião para organização do PME ocorreu em maio do mesmo ano e o $1^{\circ}$ Seminário Livre aconteceu em agosto.

Durante todo o segundo semestre de 2014 a comissão de elaboração do PME - Dourados realizou reuniões periódicas com o objetivo de elaborar o documento base do PME para discussão com a comunidade. Em Naviraí, a primeira reunião de organização do PME foi realizada em março de 2015 e todo o processo de elaboração se desenvolveu em cerca de dois meses.

São observadas, nesse caso, limitações implícitas ao próprio processo organizado em nível local, pelo qual a ação do governo municipal de Naviraí cerceia qualquer possibilidade de organização da comunidade, utilizando a participação social como forma de referendar a ação pública. Dada a limitação de tempo, pouco se pode esperar além de uma participação periférica e contingente, que não desenvolve a capacidade dos sujeitos de enfrentar questões de fundo 
relativas à temática em tela, tornando-os meramente figurantes em um processo dirigido pelo poder central do município.

O seminário final para elaboração do PME de Naviraí foi realizado nos dias 14 e 15 de maio de 2015, com participação de 220 delegados. Em Dourados tal seminário ocorreu em 23 e 24 de abril de 2015 e contou com a participação de 374 delegados. Ambos os seminários foram realizados com a participação de representantes dos mais diversos segmentos da educação básica, da educação superior, da educação profissional e dos setores e movimentos sociais.

Cerca de um mês após a realização dos Seminários em ambos os municípios, o legislativo municipal aprovou os respectivos planos municipais de educação, sob a Lei de $\mathrm{n}^{\circ} 1.933$ de 16 de junho de 2015 que “Aprova o Plano Municipal de Educação do município de Naviraí - MS e dá outras providências" (NAVIRAÍ, 2015a) e a Lei 3.904 de 23 de junho de 2015 que "Aprova o Plano Municipal de Educação do Município de Dourados do Estado do Mato Grosso do Sul, e dá outras providências" (DOURADOS, 2015a).

Em relação à tramitação da lei que aprovou as metas constantes no PME de Naviraí, a Comissão organizadora informa a realização de reunião com a Comissão de Educação da Câmara Municipal, a fim de explicar as metas e estratégias do plano (OLIVEIRA, 2017). Após a realização de tal reunião o plano foi votado sem qualquer alteração ou emenda, e aprovado pelo poder executivo sem vetos.

Processo muito diferente ocorreu no município de Dourados, cujo projeto de Lei, encaminhado pelo Prefeito à Câmara Municipal em 12 de junho de 2015, não contemplou a integralidade das metas e estratégias aprovadas em assembleia pela comunidade, uma vez que o poder executivo "retirou $20 \%$ das propostas aprovadas e modificou $80 \%$ das demais", como informa no sitio eletrônico da Câmara Municipal de Dourados (DOURADOS, 2015b).

Diante desse fato, o Sindicato Municipal dos Trabalhadores em Educação de Dourados (SIMTED) realizou reunião com o Presidente da Câmara, para solicitar a dilatação do prazo para a votação do PME de Dourados, a fim de realizar debate sobre as alterações e supressões realizadas pela Prefeitura de Dourados no documento do Plano Municipal de Educação (PME), já que o período transcorrido entre a entrega do projeto de Lei aos vereadores e a data definida para a votação era de oito dias.

Em virtude da negativa da Câmara Municipal em prorrogar o prazo para aprovação do documento, sob alegação de penalidades previstas pelo governo federal, o vereador Elias Ishy 
SCAFF, Elisangela Alves da Silva; OLIVEIRA, Marli dos Santos de; ARANDA, Flavia Paula Nogueira. Planejamento educacional e poder local na elaboração dos planos municipais de educação.

(PT), integrante da comissão de elaboração do PME-Dourados, solicitou esclarecimentos a respeito de tais penalidades. Em resposta ao questionamento, a Procuradoria Jurídica da Câmara Municipal justificou, via imprensa local, que

[...] ainda que não houvesse uma regulamentação especificando responsabilidades para os gestores de descumprissem os prazos e metas, o MEC deixou claro que os gestores podem ser submetidos a possíveis ações civis públicas, caso não sigam a legislação vigente (AGORAMS, 2015).

Devido à exiguidade do prazo para votação da pauta na Câmara Municipal de Dourados, todos os itens modificados ou suprimidos foram apresentados como emendas ao Plano Municipal de Educação, pelo mesmo vereador, totalizando mais de 190 (cento e noventa) emendas, as quais foram desconsideradas pelo conjunto de vereadores, que aprovaram o documento da forma como foi apresentado pelo executivo, em sessão plenária realizada em 23 de junho de 2015 com 14 (quatorze) votos favoráveis, 4 (quatro) votos contra e 1 (uma) ausência.

Tal sessão plenária ocorreu em meio a amplo movimento da comunidade do município de Dourados, que ocupou a Câmara Municipal em protesto às alterações realizadas pelo executivo. Entre os grupos de manifestantes destacam-se aqueles organizados em torno do Sindicato Municipal de Profissionais da Educação de Dourados (SIMTED); da Associação de Docentes da Universidade Federal da Grande Dourados (UFGD); da Seção Sindical dos Docentes da Universidade Estadual de Mato Grosso do Sul (ADUEMS) e do Diretório Central dos Estudantes (DCE) de ambas as Universidades públicas sediadas no município de Dourados.

De outro lado, também ocuparam a Câmara Municipal, na mesma data, grupos religiosos organizados em defesa da família e contra a "ideologia de gênero" que afirmavam figurar no documento. Tais grupos foram liderados por membros das pastorais da igreja católica e por pastores de igrejas evangélicas, os quais naquela mesma seção foram homenageados pelo Vereador Sergio Nogueira (PSB), que instituiu o Dia do Pastor Evangélico em Dourados.

Já no município de Naviraí, embora não tenha havido discussões ou enfrentamentos em relação à aprovação do PME, após um mês de sua aprovação, no dia 16 de julho de 2015, foi publicada no Diário Oficial dos Municípios do Estado do MS a alteração da redação dos itens 7.30, 7.31 e 16.2 da Lei de $n^{\circ} 1.933$ que aprovou o PME-NAV (2015-2024). As alterações realizadas destinaram-se à retirada da palavra gênero do texto no caso das estratégias 7.30 e 7.31 e inclusão do termo "educação em sexualidade" em substituição a "educação de gênero" na estratégia 16.2 (NAVIRAÍ, 2015b). 
A discussão em torno da temática de gênero nos planos educacionais não se limitou aos municípios de Dourados e Naviraí, mas perpassou diferentes municípios e estados. De modo análogo, o PNE (2014-2024) sofreu pressões de setores religiosos durante sua tramitação na Câmara dos Deputados em relação às questões de gênero, pois para alguns deputados, a abordagem do assunto no plano tratava-se de uma imposição à "ideologia de gênero". Dentre as questões debatidas na Câmara, consta o Artigo $2^{\circ}$, inciso III do Projeto de Lei 8.035 de 2010 (BRASIL, 2012), cujo teor defendido pela bancada cristã propugnou a erradicação de todas as formas de discriminação, enquanto os movimentos sociais explicitavam questões como igualdade racial, regional, de gênero e de orientação sexual.

Essa disputa culminou na aprovação do PNE (2014-2024) que estabelece como diretriz a redação defendida pela bancada cristã. Nota-se que esses grupos religiosos participaram do processo de decisão tanto do PNE como dos planos municipais, defendendo suas ideias e resguardando, legalmente, suas concepções religiosas e sociais.

O cenário desenhado nos municípios de Dourados e Naviraí, embora registrem itinerários diferenciados no decurso da construção dos seus respectivos planos municipais de educação, redundam em alterações significativas nos textos legais a despeito do processo participativo que perpassou sua elaboração.

Ressalve-se que tal metodologia participativa constituiu-se em premissa fundamental do governo federal nas orientações aos municípios, ao afirmar que "o PME tem de ter legitimidade para ter sucesso [...] um PME submetido ao amplo debate incorpora a riqueza das diferentes visões e vivências que a sociedade tem sobre a realidade que deseja alterar" (BRASIL, 2014a, p. 8).

Dessa forma, a indução da União torna-se um componente essencial na análise da ação local, uma vez que se trata de uma "premissa fundamental", ou seja, condição para que o PME seja reconhecido pela sociedade como resultado das demandas sociais de determinada localidade. Ao orientar a constituição das comissões e assessorar os municípios via Rede de Assistência Técnica o governo federal garante o formato participativo na elaboração dos planos, por outro lado, os governos locais, nos municípios pesquisados, tentam salvaguardar seus interesses de formas distintas, explicitando o caráter autoritário que compõe a democracia brasileira (WEFFORT, 1992). 
SCAFF, Elisangela Alves da Silva; OLIVEIRA, Marli dos Santos de; ARANDA, Flavia Paula Nogueira. Planejamento educacional e poder local na elaboração dos planos municipais de educação.

\section{Participação e poder local}

Os dados levantados nos municípios de Dourados e Naviraí revelam as disputas que se concretizaram no âmbito do poder local no processo de elaboração dos seus respectivos planos municipais de educação, evidenciando a centralidade político-administrativa do governo municipal, bem como relações de poder entre este e grupos sociais e corporativos, como os sindicatos e as organizações religiosas.

A centralidade político-administrativa do governo municipal se manifesta desde a constituição das comissões de elaboração dos planos, passando pelo tempo dedicado à elaboração do texto, pela forma como o processo foi conduzido, até a aprovação do texto final, transformado em Lei.

Quanto à coordenação das comissões, ambos os municípios designaram a membro da própria Secretaria ou Gerencia de Educação, ficando o CME na subcoordenação no caso de Naviraí e como integrante da comissão no caso de Dourados. Também nos dois municípios observa-se uma pluralidade de grupos de interesse na constituição da comissão de elaboração do PME, no entanto, a condução dos trabalhos realizada no município de Naviraí, dada a exiguidade do tempo, limitou consideravelmente a participação da comunidade local.

Participação mais ampliada ocorreu no município de Dourados, uma vez que a elaboração do documento se deu em comissões constituídas por diversos segmentos, que trabalharam durante aproximadamente um semestre na redação de cada eixo do documento, trabalho este desconsiderado pelo executivo municipal, que alterou a maior parte das metas e estratégias sem diálogo com os integrantes da comissão de elaboração do PME.

Quanto à articulação da comunidade local, dois grupos se sobressaem nos municípios pesquisados, quais sejam, os sindicatos da área de educação, com atuação mais vigorosa no município de Dourados, especialmente no confronto com o poder executivo ao alterar de forma arbitrária o teor do PME; e os grupos religiosos, precipuamente na gestão junto à Câmara Municipal de Naviraí, após a aprovação do PME, o que veio resultar na alteração da Lei com vistas a suprimir as manifestações relativas ao termo "gênero".

Esses exemplos levam a refletir sobre as considerações de Nelson e Finan (2014, p. 143), ao ponderar que a participação "não é um projeto externo cujo critério para o sucesso é definido pela presença em encontros, mas um reagrupamento interno mais profundo dentro de um grupo 
social cujo objetivo comum é claramente definido”. A organização dos grupos religiosos e dos sindicatos em torno de pautas que perpassam seus interesses e seus valores, como a família e a democracia, sugere a necessidade de despertar o interesse da sociedade sobre as pautas discutidas nos processos de elaboração de planos, de forma a assumirem essas demandas como valores fundamentais, tendo como horizonte que "o local gera capital social quando gera autoconfiança nos indivíduos de uma localidade, para que superem suas dificuldades. Gera, junto com a solidariedade, coesão social, forças emancipatórias, fontes para mudanças e transformação social" (GOHN, 2004, p. 24).

Esse movimento, no entanto, "não existe a priori” (GOHN, 2004, p. 24), também não é instintivo, célere e imediato, mas requer tempo de estudo coletivo e de amadurecimento, capacidade de organização de grupos de acordo com interesses em comum e de coordenação dos debates entre diferentes perspectivas de educação e de sociedade, de modo a criar "laços de pertencimento e identidade socio-cultural e política" (p. 24).

Para tanto, é preciso considerar que a participação em contexto local, assim como nas demais esferas, constitui-se em processo recente e ainda em construção (GOHN, 2011), cujas condições políticas tornaram inevitável uma "mistura com importantes heranças do passado autoritário" (WEFFORT, 1992, p. 6). Destarte, a elaboração dos planos municipais de educação corrobora na acepção do poder local, evidenciando suas fragilidades e também suas potencialidades, bem como arranjos locais diferenciados na gestão desses processos, que nem sempre incorporam a "nova cultura política" (GOHN, 2004, p. 28) necessária à efetivação de uma "participação cidadã" (GOHN, 2011, p. 27). Essa nova cultura

[...] se contrapõe à tradição autoritária que desconhece a existência de esferas públicas, assim como se contrapõe, também, às práticas clientelistas ou corporativas de grupos patrimonialistas, oligárquicos, ou modernos/privatistas. Trata-se de uma cultura política gerada por processos nos quais os diferentes interesses são reconhecidos, representados e negociados, via mediações sociopolíticas e culturais (GOHN, 2011, p. 28).

Nesse sentido, mais que o produto final, importa considerar a metodologia impressa ao processo de planejamento, que ao reunir a comunidade em torno de um objetivo comum, promove a criação de "laços de pertencimento social" (GOHN, 2011, p. 29), projetos e valores em comum, corroborando para uma nova "cultura política pública no país, construída a partir de critérios do campo dos direitos (sociais, econômicos, políticos e culturais), uma nova cultura ética com civilidade e respeito ao outro" (p. 28). 
Observa-se neste estudo que, apesar das orientações nacionais quanto à participação dos diversos segmentos sociais na elaboração dos PMEs, o que se manifesta no campo empírico, de formas diferentes, e em momentos distintos, é a fragilização dos processos de construção democrática. Tal fato denota que a efetivação do princípio da gestão democrática coloca-se ainda como um desafio no plano local, de forma a ultrapassar a perspectiva das "esperanças que abre, e das simbologias de que se reveste" (FERNANDES, 1992, p. 29), para concretizar práticas efetivamente participativas que promovam o empoderamento da comunidade local.

\section{Considerações finais}

A intensificação dos movimentos de mobilização da sociedade revela particularidades educacionais, regionais, culturais e políticas dos entes subnacionais, as quais influenciam na construção das práticas democráticas, explicitando as complexidades da arena política local. As disputas em torno da tramitação e aprovação dos PMEs nos municípios de Dourados e Naviraí evidenciam diferentes formas de centralidade do poder político local, cuja condução do itinerário participativo nem sempre resulta em um plano que represente o ideário dos segmentos participantes, o que reforça a fragilidade das novas democracias, apontada por Weffort (1992), as quais, por falta de "solidez institucional" (p. 8), acabam ficando em posição vulnerável diante de lideranças antidemocráticas.

As manobras antidemocráticas identificadas pelos governos municipais de Dourados e Naviraí, no entanto, ao mesmo tempo em que corroboram com a constatação de fragilidade da nossa democracia, evidenciam os limites de atuação desses governos, que embora não valorizem a participação da comunidade local, foram compelidos a envolver representantes dos mais diversos segmentos sociais do município, por indução do governo federal.

Em que pesem as limitações constatadas no resultado final desse processo, o fato de congregar parcela significativa da comunidade em torno da discussão da educação municipal corrobora para o fortalecimento do poder local e contribui na construção e desenvolvimento de espaços e práticas que, ainda de forma incipiente, promovem o aprendizado da participação social no planejamento das políticas educacionais. 
SCAFF, Elisangela Alves da Silva; OLIVEIRA, Marli dos Santos de; ARANDA, Flavia Paula Nogueira. Planejamento educacional e poder local na elaboração dos planos municipais de educação.

\section{Referências}

AGORAMS. Ao aprovar PME, Câmara previne sanções ao município, afirma Idenor. Jornal AgoraMS, Dourados, 2 de julho de 2015. Disponível em: <http://www.agorams.com.br/jornal/ 2015/07/ao-aprovarpme-camara-previne-sancoes-ao-municipio-afirma-idenor/>. Acesso em: 20 jan. 2017.

ALMEIDA JÚNIOR, Arnóbio Marques. Rumo ao Sistema Nacional de Educação. Revista Com Censo estudos educacionais do Distrito Federal, Brasília, v. 1, n. 1, p. 10-12, dez. 2014. Disponível em: $<$ http://www.cre.se.df.gov.br/ascom/documentos/suplav/revista_comcenso/ entrevista_binho_marques .pdf>. Acesso em: 20 jan. 2017.

BRASIL. Câmara dos Deputados. Projeto de Lei 8.035 de 2010 (Do Poder Executivo). 2012. Disponível em: < http://www2.camara.leg.br/atividade-legislativa/comissoes/comissoes-temporarias/especiais/54alegislatura/pl-8035-10-plano-nacional-de-educacao/documentos/outros-documentos/avulso-pl-8035-10c>. Acesso em: 15 fev. 2018.

BRASIL. O Plano Municipal de Educação: Caderno de Orientações. Brasília: MEC, 2014a. Disponível em: <file:///C:/Users/user/Desktop/artigos\%20Marli2017/pne_pme_caderno_de_orientacoes.pdf/>. Acesso em: 19 jul. 2016.

BRASIL. Casa Civil. Lei $\mathbf{n}^{\circ} \mathbf{1 3 . 0 0 5}$, de 25 de julho de 2014. Aprova o Plano Nacional de Educação PNE e da outras providências. Brasília, DF: Casa Civil, 2014b. Disponível em: <http://www.planalto.gov.br/ ccivil_03/_Ato2011-2014/2014/Lei/L13005.htm>. Acesso em: 26 ago. 2015.

DOURADOS. Resolução/SEMED n 21/2014. Constitui a comissão para Elaboração e Criação do Plano Municipal de Educação-PME do Município de Dourados-MS. Diário Oficial, Dourados, MS: Secretaria Municipal de Educação, v. 16, n. 3712, p. 2, 24 abr. 2014.

DOURADOS. Lei no 3.904, de 23 de Junho de 2015. Plano Municipal de Educação. Dourados, MS: Câmara Municipal, 2015a. Disponível em: <http://www.dourados.ms.gov.br/wp-content/uploads/ 2015/07/Lei-n\%C2\%BA-3904PME-Dourados-MS.pdf>. Acesso em: 20 out. 2015.

DOURADOS. Câmara Municipal de Dourados. Elias Ishy questiona falta de diálogo sobre o Plano Municipal de Educação. Dourados, MS: Câmara Municipal, 30 de junho de 2015b. Disponível em: <http://www.camaradourados. ms.gov.br/imprensa/elias-ishy-questiona-falta-de-dialogo-sobre-oplanomunicipal-de-educacao>. Acesso em: 19 jul. 2016.

FERNANDES, António Teixeira. Poder local e democracia. Revista da Faculdade de Letras, Porto, Portugal, v. 2, p. 29-59, 1992. Disponível em <http://ojs.letras.up.pt/index.php/Sociologia/article/ download/2613/2397>. Acesso em: 16 jul. 2016.

FERREIRA, Eliza Bartolozzi. Democracia e tecnocracia no planejamento educacional brasileiro: tensões permanentes na educação do século 21. In: FERREIRA, Eliza Bartolozzi; FONSECA, Marília. (Org.). Política e planejamento educacional no Brasil do século 21. Brasília: Liber Livro, 2013. p. 57-83.

FISCHER, Tania. Poder local: um tema em análise. Revista de Administração Pública, Rio de Janeiro, n. 26, v. 4, p. 105-113, out/dez. 1992.

FLEURY, Sonia. Políticas sociais e democratização do poder local. In: VERGARA, S. C.; CORREA, V. L. A. (Org.). Proposta para uma gestão pública municipal efetiva. Rio de Janeiro: FGV, 2003.

GOHN, Maria da Glória. Conselhos gestores e participação sociopolítica. 4. ed. São Paulo: Cortez, 2011.

GOHN, Maria da Glória. Empoderamento e participação da comunidade em políticas sociais. Saúde e Sociedade, São Paulo, v. 13, n. 2, maio/ago. 2004. 
SCAFF, Elisangela Alves da Silva; OLIVEIRA, Marli dos Santos de; ARANDA, Flavia Paula Nogueira. Planejamento educacional e poder local na elaboração dos planos municipais de educação.

IBGE. Instituto Brasileiro de Geografia e Estatística. Cidades. Rio de Janeiro: IBGE, 2016. Disponível em: <http://cod.ibge.gov.br/BKK>. Acesso em: 2 abr. 2017.

NAVIRAÍ. Altera a redação dos itens 7.30., 7.31. e 16.2 do Plano Municipal e Educação, Anexo da Lei 1.193 de 16 de junho de 2015, e da outras providências. Diário Oficial dos municípios do estado de Mato Grosso do Sul, Naviraí, n. 1388, p. 43. 16 de julho de 2015b.

NAVIRAÍ. Prefeitura Municipal de Naviraí-MS. Lei no 1.933, de16 de junho de 2015. Aprova o Plano Municipal de Educação do Município de Naviraí-MS e dá outras providências. Naviraí: Portal da Transparência. 2015a. Disponível em: <http://www.cmnavirai.ms.gov.br/portal_transparencia /Leis_Ordinarias/todos/ LEI\%20N\%C2\%BA\% 201.933,\%20DE\%2016\%20DE\%20JUNHO\%20 DE\%202015.pdf>. Acesso em: 23 fev. 2016.

NELSON, Donald R.; FINAN, Timothy J. Participação e impotência: a busca pela esperança na periferia de Fortaleza, Brasil. Iluminuras, Porto Alegre, v. 15, n. 36, p. 152-170, ago./dez. 2014. Disponível em <http://seer.ufrgs.br/index.php/iluminuras/article/viewFile/52639/32587>. Acesso em: 10 abr. 2017.

OLIVEIRA, Marli dos Santos de. Do plano nacional aos planos municipais de educação: estudo do município de Naviraí-MS. 2017. Dissertação (Mestrado em Educação) - Programa de Pós-graduação em Educação, Universidade Federal da Grande Dourados, Dourados, 2017.

PEREIRA, Jhonata Moreira; GROSSI JÚNIOR, Geraldo. A rede de assistência Técnica para elaboração ou adequação dos planos municipais de educação. In: CONGRESSO CONSAD DE GESTÃO PÚBLICA, 9., 2016, Brasília, DF. Anais... Brasília: Consad, 2016. Disponível em: <http://consad.org.br/wpcontent/uploads/2016/06/Painel-37-03.pdf>. Acesso em: 20 jan. 2017.

REDE de Assistência Técnica para Adequação ou elaboração dos planos de educação de MS.

Informativo no 003. Campo Grande, MS: UNDIME/SED/SASE/MEC, 2015a.

REDE de Assistência Técnica para Adequação ou elaboração dos planos de educação de MS.

Informativo no 006. Campo Grande, MS: UNDIME/SED/SASE/MEC, 2015 b.

WEFFORT, Francisco. Novas Democracias. Que democracias? Lua Nova: Revista de Cultura e Política, São Paulo, n. 27, p. 5-30, dez. 1992.

\author{
Elisangela Alves da Silva Scaff \\ Universidade Federal do Paraná | Departamento de Planejamento e \\ Administração Escolar (DEPLAE) \\ Curitiba | PR | Brasil. Contato: elis-scaff@ hotmail.com \\ ORCID 0000-0002-7682-0879 \\ Marli dos Santos de Oliveira \\ Universidade Federal da Grande Dourados - UFGD | Faculdade de \\ Educação (FAED) \\ Dourados | MS | Brasil. Contato: marli.oliveiras@ hotmail.com \\ ORCID 0000-0003-1440-9045 \\ Flavia Paula Nogueira Aranda \\ Universidade Federal da Grande Dourados - UFGD | Faculdade de \\ Educação (FAED) \\ Dourados | MS | Brasil. Contato: flaviaaranda@hotmail.com \\ ORCID 0000-0001-5842-1535
}

Recebido em: 19 abr. 2017 e aprovado em: 12 dez. 2017. 